\title{
Tumor necrosis factor inhibitor gene transfer ameliorates lung graft ischemia-reperfusion injury
}

\author{
Tsutomu Tagawa, MDa,b \\ Benjamin D. Kozower, MD \\ Samer A. Kanaan, MD ${ }^{a}$ \\ Niccolò Daddi, MDa \\ Takashi Suda, MD \\ Tadayuki $0 \mathrm{ka}, \mathrm{MD}^{\mathrm{b}}$ \\ G. Alexander Patterson, MD, FRCS(C) ${ }^{\mathrm{a}}$
}

See related article on page 1155.

\footnotetext{
From the Division of Cardiothoracic Surgery, Department of Surgery, ${ }^{a}$ Washington University School of Medicine, Barnes Jewish Hospital, St Louis, Mo, and the First Department of Surgery, ${ }^{\mathrm{b}}$ Nagasaki University School of Medicine, Nagasaki, Japan.

Supported by National Institutes of Health grant 1 R01 HL41281.

Received for publication Oct 2, 2002; revisions requested Dec 2, 2002; revisions received Feb 19, 2003; accepted for publication Feb 26, 2003.

Address for reprints: G. Alexander Patterson, MD, FRCS(C), Division of Cardiothoracic Surgery, Washington University School of Medicine, One Barnes-Jewish Hospital Plaza, 3108 Queeny Tower, St Louis, MO 63110-1013 (E-mail: pattersona @msnotes.wustl.edu).

J Thorac Cardiovasc Surg 2003;126: 1147-54

Copyright $(0) 2003$ by The American Association for Thoracic Surgery

$0022-5223 / 2003 \$ 30.00+0$

doi:10.1016/S0022-5223(03)00584-1
}

Objective: Tumor necrosis factor is an important mediator of lung transplant ischemia-reperfusion injury, and soluble type I tumor necrosis factor receptor binds to tumor necrosis factor and works as a tumor necrosis factor inhibitor. The objectives of this study were to demonstrate that gene transfer of type I tumor necrosis factor receptor-IgG fusion protein reduces lung isograft ischemia-reperfusion injury and to compare donor endobronchial versus recipient intramuscular transfection strategies.

Methods: Three donor groups of Fischer rats $(n=6 /$ group) underwent endobronchial transfection with either saline, $2 \times 10^{7}$ plaque-forming units of control adenovirus encoding $\beta$-galactosidase, or $2 \times 10^{7}$ plaque-forming units of adenovirus encoding type I tumor necrosis factor receptor- $\operatorname{IgG}$ fusion protein. Left lungs were harvested 24 hours later. Two recipient groups $(n=6 /$ group $)$ underwent intramuscular transfection with $2 \times 10^{7}$ plaque-forming units or $1 \times 10^{10}$ plaqueforming units of adenovirus encoding type I tumor necrosis factor receptor-IgG fusion protein 24 hours before transplantation. All donor lung grafts were stored for 18 hours before orthotopic lung transplantation. Graft function was assessed 24 hours after reperfusion. Transgene expression was evaluated by means of enzymelinked immunosorbent assay and immunohistochemistry of type I tumor necrosis factor receptor.

Results: Endobronchial transfection of donor lung grafts with $2 \times 10^{7}$ plaqueforming units of adenovirus encoding type I tumor necrosis factor receptor-IgG fusion protein significantly improved arterial oxygenation compared with the saline and $\beta$-galactosidase donor groups (366.6 \pm 137.9 vs $138.8 \pm 159.9$ and $140.6 \pm$ $131.4 \mathrm{~mm} \mathrm{Hg}, P=.009$ and .010 , respectively). Recipient intramuscular transfection with $1 \times 10^{10}$ plaque-forming units of adenovirus encoding type I tumor necrosis factor receptor-IgG fusion protein improved lung graft oxygenation compared with that seen in the low-dose intramuscular group $\left(2 \times 10^{7} ; 320.3 \pm 188.6\right.$ vs $143.6 \pm 20.2 \mathrm{~mm} \mathrm{Hg}, P=.038$ ). Type I tumor necrosis factor receptor-IgG fusion protein was expressed in endobronchial transfected grafts. In addition, intramuscular type I tumor necrosis factor receptor-IgG fusion protein expression was dose dependent.

Conclusions: Donor endobronchial and recipient intramuscular adenovirus-mediated gene transfer of type I tumor necrosis factor receptor-IgG fusion protein improved experimental lung graft oxygenation after prolonged ischemia. However, donor endobronchial transfection required 500-fold less vector. Furthermore, at low vector doses, it does not create significant graft inflammation. 




ung transplantation is an accepted treatment for end-stage lung disease. ${ }^{1}$ Unfortunately, ischemia-reperfusion injury and rejection continue to result in graft dysfunction. Although numerous studies have been performed to reduce these complications, definitive treatments have not been established. ${ }^{2}$ Gene therapy has the potential to improve clinical lung transplantation. ${ }^{3}$ Recently, our laboratory and others have demonstrated that gene transfer is feasible and improves outcome in an experimental model of lung transplantation. ${ }^{4,5}$

Tumor necrosis factor (TNF) is a proinflammatory cytokine that mediates a variety of pathologic conditions. ${ }^{6}$ It is mainly produced by macrophages and contributes to a variety of inflammatory injuries, including ischemia-reperfusion injury. ${ }^{7}$ Soluble type I TNF receptor (sTNF-RI) is a receptor for TNF- $\alpha$ and TNF- $\beta$. It has been identified in serum and urine. ${ }^{8}$ sTNF-RI binds to TNF- $\alpha$ and $\backslash$ TNF- $\beta$ and inhibits their function. ${ }^{9}$ Therefore gene transfer of sTNFRI-IgG fusion protein has the potential to inhibit the inflammatory cascade meditated by TNF and to reduce acute lung graft injury.

Several strategies have been considered for use of gene therapy in lung transplantation. These include the type of vector (eg, naked plasmid, liposome, or adenovirus), ex vivo versus in vivo gene transfer, delivery to the donor or recipient, and systemic versus local delivery strategies. Endobronchial gene transfer to the donor lung graft is an excellent localized strategy for the treatment of transplantrelated injuries, such as ischemia-reperfusion injury and graft rejection. Endobronchial gene transfer of human IL-10 ameliorates lung graft ischemia-reperfusion injury, ${ }^{10}$ and endobronchial transfection of naked transforming growth factor $\beta 1$ cDNA attenuates acute lung rejection. ${ }^{11}$ Intramuscular gene therapy to the recipient releases transgene protein into the systemic circulation and has also ameliorated experimental lung transplant injury. Recipient intramuscular gene transfer of active transforming growth factor $\beta 1$ attenuates acute lung rejection. ${ }^{12}$ Recipient intramuscular gene transfer of interleukin 10 reduces neutrophil sequestration and emigration in lung isografts. ${ }^{13}$ No studies to date have compared the efficacy of endobronchial transfection with intramuscular transfection in reducing acute lung injury. The aims of this study were to determine whether adenovirus-mediated gene transfer of sTNF-RI-IgG fusion protein decreases lung graft ischemia-reperfusion injury and to compare the efficacy of donor endobronchial transfection with that of recipient intramuscular transfection.

\section{Materials and Methods}

\section{Animals}

Fischer 344 rats (Harlan Sprague Dawley Inc, Indianapolis, Ind), weighing 250 to $280 \mathrm{~g}$, were used in all experiments. The Animal Studies Committee at Washington University approved all animal procedures. Animals received humane care in compliance with the "Guide for the Care and Use of Laboratory Animals" prepared by the National Academy of Sciences and published by the National Institutes of Health (National Institutes of Health publication no. 85-23, revised 1985).

\section{Adenoviral Vectors}

Adenovirus encoding sTNF-RI-Ig (Ad.sTNF-RI-Ig) originates from a replication-deficient recombinant type 5 adenovirus lacking the $E 1$ and $E 3$ loci. $^{14}$ sTNF-RI-Ig cDNA was inserted in place of the $E 1$ region, and expression was driven by the cytomegalovirus promoter. Ad.sTNF-RI-Ig encodes a fusion protein consisting of the extracellular domain of the human 55-kd TNF- $\alpha$ receptor and the $\mathrm{C}_{\mathrm{H}} 2$ through $\mathrm{C}_{\mathrm{H}} 3$ domains of a mouse IgG1 heavy chain. ${ }^{15}$ The adenovirus used in this study was provided as a gift from $\mathrm{Dr}$ Paul D. Robbins, Departments of Molecular Genetics and Biochemistry, University of Pittsburgh, Pittsburgh, Pa. ${ }^{16}$

The first-generation, replication-deficient, adenovirus serotype 5 carries the Escherichia coli LacZ gene (Ad.LacZ). It is driven by the constitutive cytomegalovirus promoter and encodes the enzyme $\beta$-galactosidase ( $\beta$-gal). $\beta$-gal is a nonfunctional reporter gene used as an adenovirus control (University of North Carolina, Chapel Hill, NC).

Purified viral aliquots were stored at $-70^{\circ} \mathrm{C}$ in $10 \%$ glycerol buffered with $10 \mathrm{mmol} / \mathrm{L}$ Tris, $140 \mathrm{mmol} / \mathrm{L} \mathrm{NaCl}$, and $1 \mathrm{mmol} / \mathrm{L}$ $\mathrm{MgCl}_{2}$. These stocks were thawed and diluted in sterile normal saline solution immediately before use.

\section{Experimental Design}

Two experiments were performed in this study. Experiment 1 determined the transgene expression of sTNF-RI-Ig immediately before transplantation. Experiment 2 evaluated the effect of sTNFRI-Ig gene transfection on lung graft ischemia-reperfusion injury. Both experiments had the same study groups. Fischer 344 rats were divided into 5 groups. Three donor groups underwent endobronchial transfection with either saline (endobronchial saline), 2 $\times 10^{7}$ plaque-forming units ( $\mathrm{pfu}$ ) of adenovirus control encoding $\beta$-gal (Ad.LacZ; endobronchial $\beta$-gal), or $2 \times 10^{7}$ pfu of adenovirus encoding sTNF-RI-Ig (Ad.sTNF-RI-Ig; endobronchial sTNF-RI). Two recipient groups underwent intramuscular transfection with either $2 \times 10^{7}$ pfu Ad.sTNF-RI-Ig (low-dose intramuscular group) or $1 \times 10^{10}$ pfu Ad.sTNF-RI-Ig (high-dose intramuscular group; Figure 1).

ENDOBRONCHIAL GENE TRANSFECTION OF THE DONOR. Animals were anesthetized with subcutaneous injection of ketamine chloride $(25 \mathrm{mg} / \mathrm{kg})$ and atropine sulfate $(0.25 \mathrm{mg} /$ $\mathrm{kg}$ ). After endotracheal intubation with a 14-gauge catheter, animals were mechanically ventilated with a Harvard ventilator (tidal volume, $2.5 \mathrm{~mL}$; respiratory rate, 60 breaths/ min). Donors underwent right thoracotomy, and the carina was dissected. A catheter was introduced through the endotracheal tube into the left main bronchus, and vector diluted in $0.1 \mathrm{~mL}$ of sterile normal saline solution was instilled. After 10 minutes of bilateral ventilation, the left main bronchus was clamped for 60 minutes at end-inspiratory volume. The thoracotomy was closed after removing the bronchial 


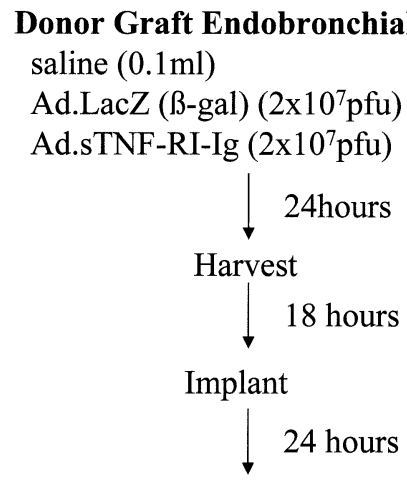

Sacrifice
(EB)

Recipient Intramuscular Delivery (IM) low dose: Ad.sTNF-RI-Ig $\left(2 \times 10^{7} \mathrm{pfu}\right)$ high dose: Ad.sTNF-RI-Ig (1x10 $\left.{ }^{10} \mathrm{pfu}\right)$

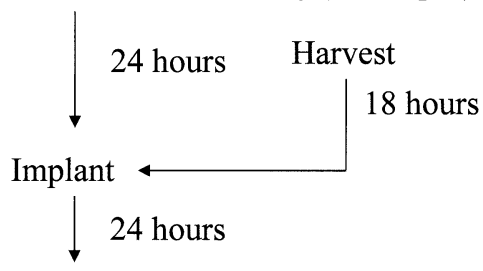

Sacrifice

Figure 1. Experimental protocol. The experimental protocol was separated by the delivery route and vector dose. Three donor groups received endobronchial transfection into the lung graft before harvest (Donor Graft Endobronchial Delivery) and 2 recipient groups received intramuscular transfection before transplantation (Recipient Intramuscular Delivery).

clamp. A temporary chest tube was placed, and the animal was recovered and extubated.

DONOR LUNG PROCUREMENT. Donor rats were anesthetized with intraperitoneal pentobarbital $(65 \mathrm{mg} / \mathrm{kg})$, mechanically ventilated, and heparinized (300 units), and a median laparosternotomy was performed. Lungs were flushed through the main pulmonary artery with $20 \mathrm{~mL}$ of cold $\left(4^{\circ} \mathrm{C}\right)$ low potassium dextran glucose solution at $20 \mathrm{~cm}$ $\mathrm{H}_{2} \mathrm{O}$ pressure. The heart-lung block was removed with the lungs inflated at end-inspiratory volume. The left lung was isolated and stored at $4^{\circ} \mathrm{C}$ for 18 hours before implantation.

RECIPIENT INTRAMUSCULAR GENE TRANSFER. Animals were anesthetized with halothane, and vector dissolved in $1 \mathrm{~mL}$ of saline was injected into the right gastrocnemius muscle. Animals were recovered and transplanted 24 hours later.

\section{Experiment 1: sTNF-RI-Ig Expression Before Transplantation}

In all 3 donor endobronchial groups ( $\mathrm{n}=3$ /group), donor lung grafts were harvested 24 hours after transfection, and sTNF-RI-Ig transgene expression was measured by using an sTNF-RI enzymelinked immunosorbent assay (ELISA). Immunohistochemistry of sTNF-RI was performed to document epithelial cell transgene expression. In addition, for the endobronchial sTNF-RI group, we measured transgene expression in donor lung grafts after 18 hours of cold preservation and in the nontreated donor right lung at the time of harvest.

In both recipient intramuscular groups ( $n=3$ /group), sTNFRI-Ig transgene expression in serum and in the right gastrocnemius muscle was evaluated 24 hours after gene transfection by using sTNF-RI ELISA.

STNF-RI ELISA. Lung and muscle samples were homogenized with a lysis solution consisting of $100 \mathrm{mmol} / \mathrm{L}$ potassium phosphate dibasic, $\mathrm{pH} 7.8$, including $0.2 \%$ Triton X-100 (Fisher Scientific, Fair Lawn, NJ), $5 \mu \mathrm{g} / \mathrm{mL}$ Pepsta- tin A (Boehringer-Mannheim, Indianapolis, Ind), and the protease inhibitor Complete Mini (Roche, Inc, Nutley, NJ). After 15 minutes at room temperature, the extraction was centrifuged at $11,000 \mathrm{~g}$ for 10 minutes at $4^{\circ} \mathrm{C}$. Serum samples were obtained by means of centrifugation of arterial blood samples at $1,000 \mathrm{~g}$ for 10 minutes at $4^{\circ} \mathrm{C}$. A human sTNF-RI ELISA kit was used (R\&D Systems Inc, Minneapolis, Minn). There is no cross-reactivity between the human and rat sTNF-RI proteins. Optical density was determined by using an Ultra Microplate Reader (EL808; Bio-Tek Instruments, Inc, Winooski, Vt) set to $450 \mathrm{~nm}$. Total soluble protein (in picograms per milligram of total protein) was determined by using the method of Pierce Laboratories (Rockford, Ill). ${ }^{17}$

IMMUNOHISTOCHEMISTRY OF sTNF-RI. Tyramide Signal Amplification Biotin System kits (NEN Life Science Products, Inc, Boston, Mass) were used for immunohistochemistry. Briefly, lungs were perfused with $20 \mathrm{~mL}$ of normal saline and $20 \mathrm{~mL}$ of HistoChoice (Amresco, Solon, Ohio). Specimens were fixed, cut, mounted, deparaffinized, and then treated with Dako Target Retrieval Solution (Dako, Carpinteria, Calif). Sections were incubated for 60 minutes with an Fc $\gamma$ II receptor blocker (BD PharMingen, San Diego, Calif) and with Super Block Blocking Buffer (Pierce Chemical Co). Sections were then incubated overnight with a biotinylated goat anti-human sTNF-RI polyclonal antibody (BD PharMingen) at 1:20 dilution in TNB Blocking Buffer at $4^{\circ} \mathrm{C}$. Next, slides were incubated with Streptavidin-Alkaline Phosphatase (NEN Life Science Products, Inc). Specific binding was detected by using the BCIP/NBT substrate working solution (Vector Laboratories, Inc, Burlingame, Calif) containing $5 \mathrm{mmol} / \mathrm{L}$ levamisole (Vector Laboratories, Inc). Slides were then counterstained with 


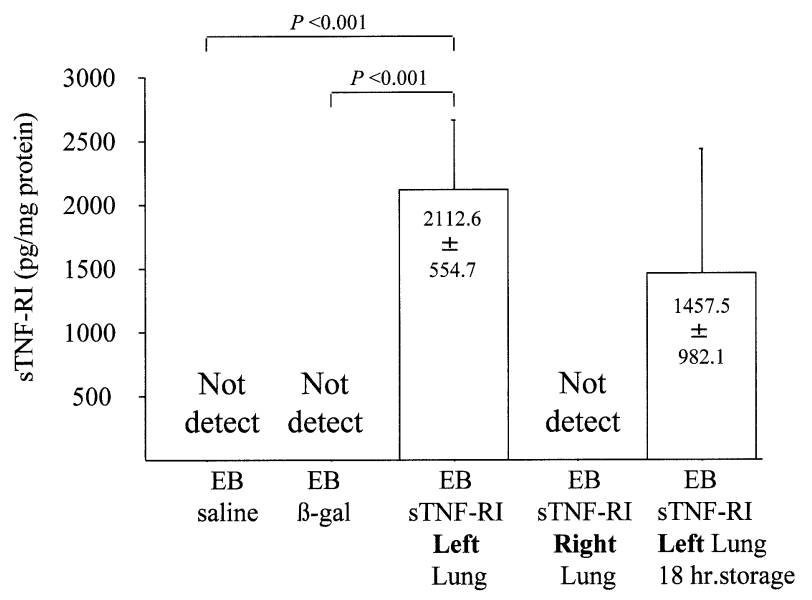

Figure 2. Lung graft expression of sTNF-RI-Ig after endobronchial transfection. Twenty-four hours after endobronchial transfection, sTNF-RI-Ig expression was significantly higher in the endobronchial (EB) sTNF-RI group. This expression was specific to the transfected left lung, and there was no expression in the untreated right lung. In addition, sTNF-RI-Ig expression is maintained during prolonged, 18-hour, cold ischemia. Isografts in the other endobronchial groups showed no significant gene expression.

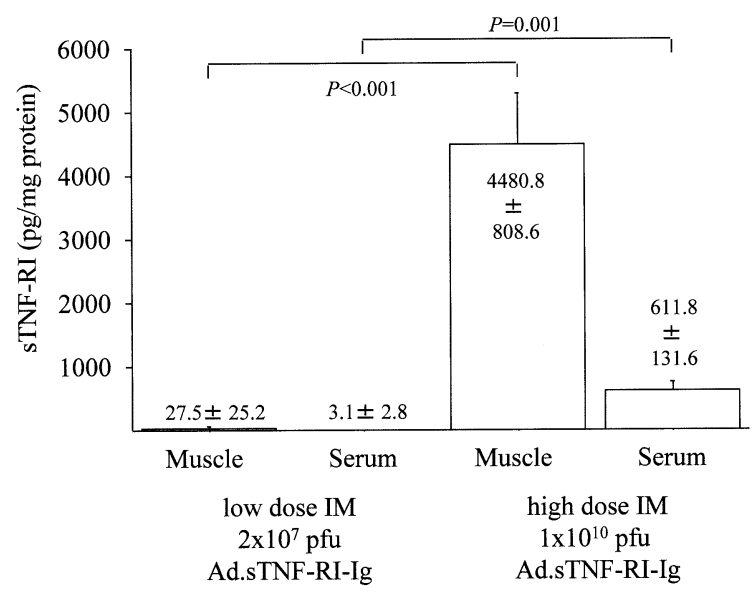

Figure 3. Serum and muscle expression of sTNF-RI-Ig after intramuscular transfection of Ad.sTNF-RI-lg. The muscle and serum sTNF-RI-Ig expression was almost 200 -fold greater in the highdose intramuscular $(I M)$ group $\left(1 \times 10^{10} \mathrm{pfu}\right)$ than in the low-dose intramuscular group $\left(2 \times 10^{7} \mathrm{pfu}\right)$.

nuclear fast red, dehydrated, and mounted, and cover slips were placed.

\section{Experiment 2: The effect of STNF-RI-Ig gene} transfection on lung graft ischemia-reperfusion injury In the 3 donor endobronchial groups ( $n=6 /$ group), donor lung grafts were harvested 24 hours after transfection. In both recipient intramuscular groups ( $n=6$ /group), orthotopic left lung transplan- tation was performed 24 hours after gene transfection. All donor lungs were flushed and stored in low potassium dextran glucose solution for 18 hours at $4^{\circ} \mathrm{C}$ before transplantation.

Recipient animals were anesthetized and intubated with a 14gauge catheter, and a left thoracotomy was performed. The pulmonary vessels and bronchus were dissected, and the lung graft was anastomosed by using the modified cuff technique. ${ }^{18}$

Twenty-four hours after reperfusion, recipient animals were reanesthetized with pentobarbital. Animals were mechanically ventilated through a tracheostomy with $100 \%$ oxygen. The right main bronchus and pulmonary artery were clamped to isolate the left lung graft. Animals were ventilated for 5 minutes at a tidal volume of $1.5 \mathrm{~mL}$, a respiratory rate of $100 \mathrm{breaths} / \mathrm{min}$, and a peak end-expiratory pressure of $1.0 \mathrm{~cm} \mathrm{H}_{2} \mathrm{O}$. An arterial blood gas analysis was performed, and the lungs were flushed with $20 \mathrm{~mL}$ of $4^{\circ} \mathrm{C}$ saline solution. Left lung grafts were divided into 3 sections: the upper third was used for ELISA of sTNF-RI and rat TNF- $\alpha$ after reperfusion, the middle third was used for myeloperoxidase (MPO) activity measurement, and the lower third was weighed, dried at $80^{\circ} \mathrm{C}$ for 48 hours, and then reweighed for calculation of the wet/dry weight ratio. Serum from all groups and transfected right gastrocnemius muscles from both recipient intramuscular groups was used for ELISA of sTNF-RI.

MPO ACTIVITY. Quantitative MPO activity was determined as previously described. ${ }^{19}$ One unit of enzyme activity was defined as 1.0 optical density units per minute per milligram of tissue protein at room temperature.

ELISA OF RAT TNF-A. Reperfused lung grafts from all 5 groups were used for ELISA of endogenous rat TNF- $\alpha$, as described earlier for sTNF-RI. The rat TNF- $\alpha$ ELISA kit was purchased from R\&D Systems, Inc.

\section{Statistical analysis}

All values are described as means \pm SD. Data not normally distributed were analyzed after logarithmic correction. One-way analysis of variance with pairwise comparison by using the Fisher least significant difference was used to compare the differences among multiple groups.

\section{Results \\ Experiment 1}

ELISA OF STNF-RI AFTER STNF-RI-IG GENE TRANSFER. Significant transgene expression of sTNF-RI-Ig was detected in left lungs from the endobronchial sTNF-RI group but not from the other endobronchial groups. In addition, there was no sTNF-RI-Ig expression detected in the rights lungs of the endobronchial sTNF-RI group (Figure 2). In the recipient intramuscular groups, serum and muscle sTNF-RI-Ig transgene expression was dose dependent (Figure 3).

IMMUNOHISTOCHEMISTRY OF STNF-RI IN THE LUNG. Positive immunohistochemical staining for sTNF-RI was observed in Ad.sTNF-RI-Ig endobronchially transfected lungs. The distribution of expression was increased in the hilar bronchus compared with the alveoli in the peripheral lung (Figure 4, A). Staining was detected in epithelial cells 



Figure 4. Immunohistochemistry of human sTNF-RI in rat lungs after endobronchial transfection of Ad.sTNF-RI-Ig. Heterogeneous staining was observed in alveoli $(A$, original magnification $40 \times)$. Epithelial cells of the bronchus, bronchioles, and alveoli show sTNF-RI staining, but endothelial, smooth muscle, and interstitial cells do not ( $B$, original magnification $100 \times$ ).

of the bronchi and alveolar cells but was not detected in endothelial, smooth muscle, or interstitial tissue cells (Figure $4, B)$. As expected, no sTNF-RI staining was present in lungs transfected with $\beta$-gal or saline solution because these vectors do not contain the human gene encoding sTNF-RI.

DEGREE OF NEUTROPHIL INFILTRATION INTO LUNG GRAFTS AFTER Ad.sTNF-RI-Ig tRANSFeCtion. The MPO activity in lung tissue 24 hours after endobronchial transfection was quantified to measure the effect of this adenovirus-mediated transfection strategy on neutrophil infiltration (a reflection of inflammation). There was no significant difference in MPO between grafts transfected with Ad.sTNF-RI-Ig and untreated control grafts $(0.099 \pm 0.047$ vs $0.076 \pm 0.020$ $\Delta \mathrm{OD} \cdot \mathrm{min}^{-1} \cdot \mathrm{mg}^{-1}$ protein, $P=.286$ ).

\section{Experiment 2}

ISOLATED LUNG ISOGRAFT GAS EXCHANGE. Endobronchial transfection of $2 \times 10^{7}$ pfu of Ad.sTNF-RI-Ig (endobronchial sTNF-RI) significantly improved $\mathrm{PaO}_{2}$ levels compared with those in the control endobronchial groups. Importantly, the $\mathrm{PaO}_{2}$ for the endobronchial sTNF-RI group was significantly higher than that for the low-dose intramuscular group treated with the same dose of $2 \times 10^{7}$ pfu of Ad.sTNF-RI-Ig (Figure 5). There were no significant differences in the mean carbon dioxide levels between the groups $(P>.122)$.

WET/DRY WEIGHT RATIO. The wet/dry weight ratio is an indicator of tissue edema. The endobronchial sTNF-RI group and the high-dose intramuscular group had a trend toward lower wet/dry ratios, reflecting less tissue edema, than the other groups $(6.15 \pm 0.57$ and $6.46 \pm 0.73$ vs 6.56 $\pm 0.87,7.06 \pm 1.97$, and $7.29 \pm 0.69$, respectively; $P=$ $.083)$.

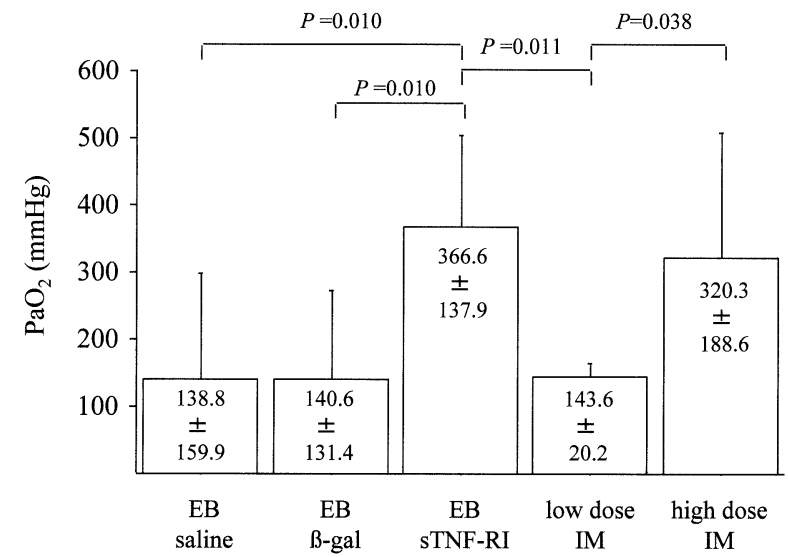

Figure 5. Isolated lung graft oxygenation 24 hours after reperfusion. Twenty-four hours after reperfusion, the right hilum was clamped, and the left lung was ventilated with $100 \%$ oxygen for 5 minutes. The endobronchial (EB) sTNF-RI group had superior arterial oxygenation $\left(\mathrm{PaO}_{2}\right)$ compared with the control endobronchial groups and the low-dose intramuscular (IM) group (receiving the same vector dose of $2 \times 10^{7} \mathrm{pfu}, P<.011$ ). The high-dose intramuscular group $\left(1 \times 10^{10} \mathrm{pfu}\right)$ had a similar improvement in $\mathrm{PaO}_{2}$ to that seen in the endobronchial sTNF-RI group but required 500 times more vector.

MPO ACTIVITY AFTER LUNG GRAFT REPERFUSION. MPO activity 24 hours after reperfusion is a reflection of neutrophil infiltration into lung grafts. ${ }^{19}$ Lung graft MPO levels were reduced in the endobronchial sTNF-RI group compared with in the endobronchial saline group $(0.106 \pm$ 0.045 vs $0.298 \pm 0.142 \Delta \mathrm{OD} \cdot \mathrm{min}^{-1} \cdot \mathrm{mg}^{-1}$ protein, $P=$ $.004)$. There were no significant differences between the other groups $(P>.059)$ The values were $0.323 \pm 0.478$ in 


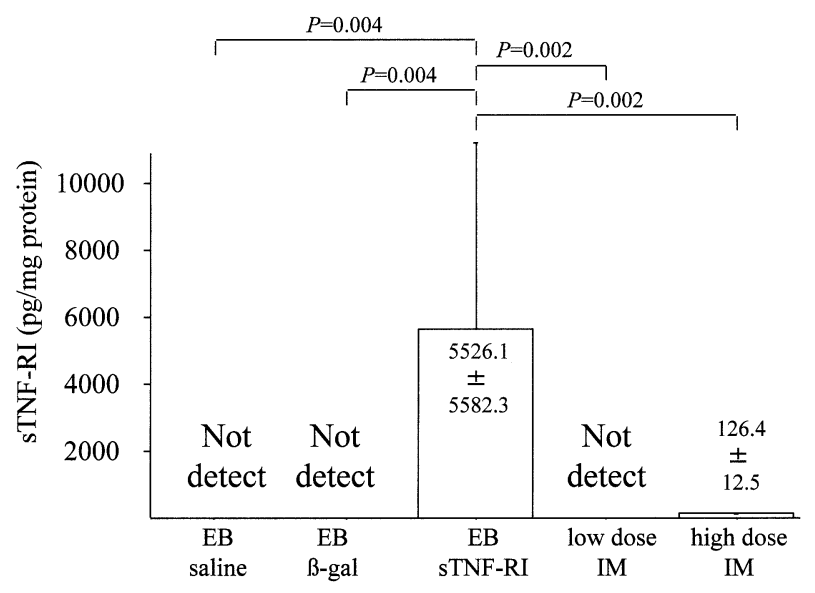

Figure 6. Lung graft expression of sTNF-RI-Ig after reperfusion. Twenty-four hours after lung graft reperfusion, sTNF-RI-Ig expression in the lung graft was significantly higher in the endobronchial (EB) sTNF-RI group than in the recipient intramuscular (IM) groups or the control endobronchial groups $(P<.004)$.

the endobronchial $\beta$-gal group, $0.171 \pm 0.056$ in the lowdose intramuscular group, and $0.156 \pm 0.037$ in the highdose intramuscular group (in $\Delta$ optical density units per minute per milligram).

ELISA of STNF-RI. The extracts derived from muscle, lung, and serum 24 hours after reperfusion were used for the measurement of sTNF-RI. Transgene expression of sTNFRI-Ig in the muscles and serum samples of the intramuscular groups was dose dependent. sTNF-RI in muscle was 8.3 $\pm 6.2 \mathrm{pg} / \mathrm{mg}$ protein in the low-dose intramuscular group and $4586.7 \pm 834.3 \mathrm{pg} / \mathrm{mg}$ protein in the high-dose intramuscular group. sTNF-RI in serum was $1.3 \pm 1.5 \mathrm{pg} / \mathrm{mg}$ protein in the low-dose intramuscular group and $1029.8 \pm$ $302.5 \mathrm{pg} / \mathrm{mg}$ protein in the high-dose intramuscular group. The lung grafts of the endobronchial sTNF-RI group expressed large amounts of sTNF-RI-Ig during reperfusion. A small amount of sTNF-RI-Ig was also detected in lung grafts of the high-dose intramuscular group 24 hours after reperfusion (Figure 6).

ELISA OF RAT TNF-A. The endogenous rat TNF- $\alpha$ levels in reperfused lung grafts were measured to determine the effect of sTNF-RI-Ig transfection on the production of this proinflammatory cytokine. The endogenous TNF- $\alpha$ levels were significantly lower in the endobronchial sTNF-RI group than in the endobronchial saline group $(2.39 \pm 1.46$ vs $10.15 \pm 9.94 \mathrm{pg} / \mathrm{mg}$ protein, $P=.013$ ) but not significantly different than in the other groups. The values of the endobronchial $\beta$-gal, low-dose intramuscular, and highdose intramuscular groups were as follows: $6.79 \pm 4.86$, $4.63 \pm 1.53$, and $3.01 \pm 0.86 \mathrm{pg} / \mathrm{mg}$ protein $(P=.144$, .450 , and .832 , respectively).

\section{Discussion}

Ischemia-reperfusion injury is inevitable during lung transplantation and is the most important predictor of early postoperative morbidity and mortality. ${ }^{20}$ Severe graft dysfunction prolongs the length of stay in the intensive care unit and might require extracorporeal membrane oxygenation. $^{21,22}$ The pathophysiology of this acute lung injury is complex. One important factor that influences the degree of ischemia-reperfusion injury is the release of proinflammatory cytokines. ${ }^{23}$

TNF is an important proinflammatory cytokine that regulates many biologic functions, including normal host resistance to infection, malignant tumor growth, and the induction of the inflammatory response. ${ }^{6}$ TNF also plays a crucial role in inducing lung transplantation ischemia-reperfusion injury. ${ }^{23}$ Two kinds of TNF receptors have been identified, type I (p55) and type II (p75), that specifically bind TNF with equal affinity. ${ }^{24}$ These soluble receptors are capable of neutralizing and modulating the biologic activity of TNF. ${ }^{8}$ This study evaluated the ability of adenovirusmediated gene transfer of sTNF-RI-Ig to inhibit TNF and reduce acute lung injury. Previous studies from our laboratory and others have demonstrated the feasibility of gene therapy in the field of lung transplantation. ${ }^{4,5}$ We have used several delivery strategies to reduce ischemia-reperfusion injury, including the intravenous, ${ }^{25}$ intramuscular, ${ }^{13}$ and endobronchial ${ }^{10}$ routes. However, the amount of vector and the efficacy of these delivery routes had not been compared.

In the present study both endobronchial transfection $(2 \times$ $\left.10^{7} \mathrm{pfu}\right)$ of the donor and high-dose $\left(1 \times 10^{10} \mathrm{pfu}\right)$ intramuscular transfection of the recipient with Ad.sTNF-RI-Ig improved lung graft oxygenation. Adenovirus-mediated gene transfer of sTNF-RI-Ig produces sTNF-RI protein, which inhibits the proinflammatory effects of TNF. In addition, endobronchial Ad.sTNF-RI-Ig transfection reduced neutrophil infiltration into lung grafts and reduced the expression of endogenous rat TNF- $\alpha 24$ hours after reperfusion. In the intramuscular transfection groups neutrophil sequestration and endogenous rat TNF- $\alpha$ expression was lower than in the endobronchial control groups but not significantly different from each other.

The lung ELISA data for sTNF-RI provides a probable explanation for these results. The endobronchial Ad.sTNFRI-Ig and high-dose intramuscular recipient groups both have transgene expression in the lung 24 hours after lung graft reperfusion. However, the endobronchial Ad.sTNFRI-Ig group had 50-fold higher gene expression than the high-dose intramuscular recipient group. Therefore the endobronchial transfected group has a much higher amount of sTNF-RI-Ig in the lung graft to inhibit the function of TNF strongly and to improve lung graft function.

The donor endobronchial dose of $2 \times 10^{7}$ pfu and the recipient intramuscular dose of $1 \times 10^{10}$ pfu have been 
examined in previous reports. ${ }^{10,13}$ Endobronchial transfection with $2 \times 10^{6}$ pfu did not improve lung graft oxygenation, and greater than $1 \times 10^{8} \mathrm{pfu}$ produced macroscopic lung edema, atelectasis, and inflammation. ${ }^{10}$ In addition, the relatively low adenoviral vector dose of $2 \times 10^{7}$ pfu has been shown to result in minimal epithelial inflammation. ${ }^{10}$ Immunohistochemistry in the endobronchially transfected lungs showed heterogeneous and patchy staining of sTNF-RI in epithelial cells. Because the majority of ischemia-reperfusion injury occurs in endothelial cells, endobronchial gene transfer might work in a paracrine manner. ${ }^{10}$ A potential side effect of endobronchial transfection is local inflammation. However, this protocol uses low-dose adenovirus gene transfer to limit this complication. Furthermore, MPO activity, a reflection of neutrophil infiltration, is not increased in Ad.sTNF-RI-Ig-treated lungs.

The low-dose intramuscular recipient group received the same amount of vector $\left(2 \times 10^{7} \mathrm{pfu}\right)$ as the endobronchial Ad.sTNF-RI-Ig group but did not have improved lung graft function. In fact, an intramuscular dose of $1 \times 10^{10} \mathrm{pfu}, 500$ times more vector, was required to achieve similar results. These data demonstrate that intramuscular gene delivery requires significantly more vector than a targeted endobronchial delivery strategy. The use of less adenoviral vector decreases costs, reduces local inflammation, and reduces the cellular and humoral immune response. ${ }^{26}$ Furthermore, Our laboratory has recently demonstrated that endobronchial gene transfer is indeed very selective. Endobronchial delivery of adenovirus-mediated $\beta$-gal produced excellent $\beta$-gal expression in the lung and negligible expression in the serum, muscle, liver, kidney, heart, and spleen. ${ }^{27}$

After intramuscular gene delivery, myocytes produce the transgene and release it into the systemic circulation to work in an endocrine manner. ${ }^{28}$ Although it requires more vector than an endobronchial approach and exposes the systemic circulation to the adenovirus vector, it might serve a role in improving lung transplantation. ${ }^{12,13,29}$ The merits of intramuscular transfection are the ease of administration and the benefit of not introducing adenoviral vector directly into the lung graft. In addition, it would be relatively easy to treat the transplant recipient at one's own institution as soon as a donor organ is identified.

The main limitation of this study is that gene transfer was performed 24 hours before lung harvest (endobronchial groups) and transplantation (intramuscular groups). Because reperfusion injury begins immediately, gene expression is required at the time of reperfusion to reduce acute lung injury. By using current vector technology, 24 hours is needed for adequate transgene expression.

In conclusion, adenovirus-mediated gene transfer of sTNF-RI-Ig produces sTNF-RI protein, inhibits TNF, and ameliorates experimental ischemia-reperfusion injury. sTNF-RI-Ig gene transfer improves lung graft oxygenation when delivered endobronchially to donor lung grafts and by intramuscular transfection to transplant recipients. However, endobronchial transfection is significantly more efficient, requiring 500-fold less vector than intramuscular gene transfer. Furthermore, at low vector doses it does not create significant graft inflammation. It is a selective transfection strategy that limits systemic vector exposure and warrants further investigation.

We thank Dr Paul D. Robbins, Departments of Molecular Genetics and Biochemistry, School of Medicine, University of Pittsburgh, for kindly providing adenovirus encoding Ad.sTNFRI-Ig. We also thank Richard B. Schuessler, PhD, for his statistical advice. Finally, we thank Kathleen Grapperhaus for technical assistance and Dawn Schuessler and Mary Ann Kelly for secretarial support.

\section{References}

1. Patterson GA, Cooper JD. Lung transplantation. Chest Surg Clin North Am. 1993;3:1-173.

2. Meyers BF, Lynch JP, Trulock EP, Guthrie TJ, Cooper JD, Patterson GA. Lung transplantation: a decade of experience. Ann Surg. 1999; 230:362-70.

3. Kaiser LR, Albelda SM. Gene transfer and thoracic surgery: more to come. Ann Thorac Surg. 1997;63:1527-8.

4. Boasquevisque CH, Mora BN, Schmid RA, Lee TC, Cooper JD, Patterson GA, et al. Ex vivo adenoviral-mediated gene transfer to lung isografts during cold preservation. Ann Thorac Surg. 1997;63:155661.

5. Cassivi SD, Cardella JA, Fischer S, Liu M, Slutsky AS, Keshavjee S. Transtracheal gene transfection of donor lungs prior to organ procurement increases transgene levels at reperfusion and following transplantation. J Heart Lung Transplant. 1999;18:1181-8.

6. Beutler B, Cerami A. Tumor necrosis, cachexia, shock, and inflammation: a common mediator. Annu Rev Biochem. 1988;57:505-18.

7. Khimenko PL, Bagby GJ, Fuseler J, Taylor AE. Tumor necrosis factor- $\alpha$ in ischemia and reperfusion injury in rat lungs. J Appl Physiol. 1998;85:2005-11.

8. Olsson I, Lantz M, Nilsson E, Thysell H, Grubb A, Adolf G, et al. Isolation and characterization of a tumor necrosis factor binding protein from urine. Eur J Haematol. 1989;42:270-5.

9. Aderka D, Engelmann H, Shemer-Avni Y, Galil A, Sarov B, Wallach $\mathrm{D}$, et al. Variation in serum levels of the soluble TNF receptors among healthy individuals. Lymphokine Cytokine Res. 1992;11:157-9.

10. Tagawa T, Suda T, Daddi N, Kozower BD, Kanaan SA, Patterson GA, et al. Low-dose endobronchial gene transfer to ameliorate lung graft ischemia-reperfusion injury. J Thorac Cardiovasc Surg. 2002;123: 795-802.

11. D'Ovidio F, Yano M, Ritter JH, Mohanakumar T, Patterson GA. Endobronchial transfection of naked TGF- $\beta 1$ cDNA attenuates acute lung rejection. Ann Thorac Surg. 1999;68:1008-13.

12. Suda T, D'Ovidio F, Daddi N, Ritter JH, Mohanakumar T, Patterson GA. Recipient intramuscular gene transfer of active transforming growth factor- $\beta 1$ attenuates acute lung rejection. Ann Thorac Surg. 2001;71:1651-6.

13. Kozower BD, Kanaan SA, Tagawa T, Suda T, Daddi N, Patterson GA, et al. Recipient intramuscular gene transfer of interleukin-10 reduces neutrophil sequestration and emigration in lung isografts. Am J Transplant. 2002;2:837-42.

14. Yeh P, Perricaudet M. Advances in adenoviral vectors: from genetic engineering to their biology. FASEB J. 1997;11:615-23.

15. Kolls J, Peppel K, Silva M, Beutler B. Prolonged and effective blockade of tumor necrosis factor activity through adenovirus-mediated gene transfer. Proc Natl Acad Sci U S A. 1994;91:215-9.

16. Ghivizzani SC, Lechman ER, Kang R, Tio C, Evans CH, Robbins PD, et al. Direct adenovirus-mediated gene transfer of interleukin 1 and 
tumor necrosis factor $\alpha$ soluble receptors to rabbit knees with experimental arthritis has local and distal anti-arthritic effects. Proc Natl Acad Sci U S A. 1998;95:4613-8.

17. Smith PK, Krohn RI, Hermanson GT, Mallia AK, Olson BJ, Klenk DC, et al. Measurement of protein using bicinchoninic acid. Anal Biochem. 1985;150:76-85.

18. Mizuta T, Kawaguchi A, Nakahara K, Kawashima Y. Simplified rat lung transplantation using cuff technique. J Thorac Cardiovasc Surg. 1989;97:578-81.

19. Krawisz JE, Sharon P, Stenson WF. Quantitative assay for acute intestinal inflammation based on myeloperoxidase activity: assessment of inflammation in rat and hamster models. Gastroenterology. 1984; 87:1344-50.

20. Kelly KJ, Bonventre JV. Ischemia/reperfusion injury in transplantation. In: Tilney NL, Strom TB, Paul LC, editors. Transplantation biology: cellular and molecular aspects. Philadelphia: LippincottRaven; 1996. p. 257-74.

21. Lee KH, Martich GD, Boujoukos AJ, Keenan RJ, Griffith BP. Predicting ICU length of stay following single lung transplantation. Chest. 1996;110:1014-7.

22. Meyers BF, Sundt TM 3rd, Trulock EP, Guthrie T, Cooper JD, Patterson GA, et al. Selective use of extracorporeal membrane oxygenation is warranted after lung transplantation. $J$ Thorac Cardiovasc Surg. 2000;120:20-6.
23. Sundaresan S, Alevy YG, Steward N, Tucker J, Trulock EP, Cooper $\mathrm{JD}$, et al. Cytokine gene transcripts for tumor necrosis factor-alpha, interleukin-2, and interferon-gamma in human pulmonary alografts. J Heart Lung Transplant. 1995;14:512-8.

24. Tartaglia LA, Goeddel DV. Two TNF receptors. Immunol Today. 1992;13:151-3.

25. Itano H, Zhang W, Ritter JH, McCarthy TJ, Mohanakumar T, Patterson GA. Adenovirus-mediated gene transfer of interleukin 10 ameliorates reperfusion injury of rat lung isografts. $J$ Thorac Cardiovasc Surg. 2000;120:947-56.

26. Yang Y, Li Q, Ertl HCJ, Wilson JM. Cellular and humoral immune responses to viral antigens create barriers to lung-directed gene therapy with recombinant adenoviruses. $J$ Virol. 1995;69:2004-15.

27. Kannan SA, Kozower BD, Suda T, Daddi N, Tagawa T, Patterson GA, et al. Intratracheal adenovirus-mediated gene transfer is optimal in experimental lung transplantation. J Thorac Cardiovasc Surg. 2002; 124:1130-6.

28. Blau HM, Springer ML. Gene therapy-a novel form of drug delivery. N Engl J Med. 1995;2:1204-7.

29. Wolff JA, Malone RW, Williams P, Acsadi G, Jani A, Felgner PL, et al. Direct gene transfer into mouse muscle in vivo. Science. 1990;247: 1465-8. 